\title{
WTO Accession and Performance of Chinese Manufacturing Firms: Corrigendum
}

\author{
By Loren Brandt, Johannes Van Biesebroeck, Luhang Wang, \\ AND YIFAN ZHANG*
}

In the course of ongoing research, we discovered a programming mistake in the construction of the input price deflator that we used in our 2017 AER article. This deflator is a building block of our two firm-level performance measures, markups, and productivity. Using a corrected deflator changes the point estimates in several of our original tables to some extent. However, only one of the key insights regarding the effect of input and output tariffs on firm or industry outcomes needs to be revised.

The results regarding the impact of changes in tariffs on markups remain unchanged. Input tariff cuts raise firm markups, while output tariff cuts reduce markups. The findings on the productivity-enhancing effects of input tariff cuts are also robust, both at the firm and industry levels. And we still find that, at the industry level, output tariff cuts raise productivity, primarily through their effect on new entrants. However, we no longer have definitive evidence for a positive impact of output tariff cuts on the productivity of incumbent firms.

In particular, in the updated firm-level regression results of Table 3, the effect of the output tariff on productivity (TFP) is not statistically significantly different from 0 . At the industry level, however, the effect continues to be significant as shown in the updated results of Table 4. The reason for the difference is straightforward. Tariff cuts are now estimated to have a weaker impact on the productivity of incumbent firms, but continue to make a positive contribution through the evolution of the productivity of newly entering firms.

In the remainder of this document we detail the nature of the mistake and the impact it had on the input price deflator used in the analysis. We provide new versions of Table 3 and Table 4 that contain the updated firm-level and industry-level analyses identified from changes within industries over time, and of Table 7 with updated regression results for performance levels, i.e., without firm-fixed effects. We discuss the impact of the changes in estimates on the findings and the conclusions we took away from the analysis.

\footnotetext{
* Brandt: Department of Economics, University of Toronto, 150 St. George Street, Toronto, ON M5S 3G7, Canada (email: brandt@chass.utoronto.ca); Van Biesebroeck: Department of Economics, KU Leuven, Naamsestraat 69, 3000 Leuven, Belgium, and CEPR (email: jo.vanbiesebroeck@kuleuven.be); Wang: Department of International Economics and Trade, Xiamen University, Economics Building, 361005 Xiamen, China, and Wang Yanan Institute for Studies in Economics (email: luhangwang@xmu.edu.cn); Zhang: Department of Economics, Chinese University of Hong Kong, Shatin, N.T., Hong Kong (email: yifan.zhang@cuhk.edu.hk).

${ }^{\dagger}$ Go to https://doi.org/10.1257/aer.20121266 to visit the article page for additional materials and author disclosure statement(s).
} 


\section{Corrected Input Price Deflator}

We construct the input price deflator for each industry as a weighted average of the output deflators of all manufacturing industries, using as weights the input shares from the 2002 National Input-Output (IO) table. Since the IO table is at a less-detailed industry level than the Chinese Industrial Classification (CIC), we first calculate an aggregate output price index for each IO sector by taking an output-weighted average of the underlying CIC industry prices. The input price deflator for each IO sector is then an input-share weighted average of these output deflators.

In assigning the resulting input price deflators to the original (CIC) industries, we mistakenly used a concordance file that ignored the first few sectors in the IO table, which refer to agriculture activities. As a result, all CIC four-digit industries were assigned the input price deflator of the IO sector six positions further down in the IO sector classification. For example, all the four-digit CIC industries that are mapped in the IO sector 13 "grain milling" were mistakenly assigned the input price deflator of IO sector 19 "other food processing and food manufacturing." The output deflators were not affected. An updated data file containing the corrected input price deflator is available for download on the AER's website. ${ }^{1,2}$

\section{Updated Estimates}

The input deflator is used in the construction of both of our firm-level performance measures. Since the markup variable only depends on the input price deflator through an adjustment of the nominal material share with the residual from the production function, the results using the markup as the dependent variable are largely unchanged. The results using productivity as the dependent variable are affected to a greater extent because deflated material inputs are one of the production factors and the estimates of the parameters in the production function are affected as well.

Four of the seven tables in the original article are affected, but none of the figures. Below, we summarize changes in each of these tables after re-running all analyses with the updated input price deflator.

Table 1.-Changes in all point estimates are minor, and no coefficient changes in either sign or statistical significance. Economic magnitudes of all effects are virtually unchanged.

Table 3(a).-Changes are minor in panel A, where the firm-level markup is the dependent variable. All point estimates are affected slightly, but absolute magnitudes are very similar as before and no coefficient changes in signs. Only two statistically significant coefficients become insignificant and these are for point estimates on input tariffs that were not the focus of the discussion.

\footnotetext{
${ }^{1}$ Because the number of firms differs by industry, the average input price deflator across all firms in the sample has changed.

${ }^{2}$ The input price deflator used in Brandt, Van Biesebroeck, and Zhang (2012) was similarly affected by this mistake. However, that analysis focused on the average productivity evolution across sectors, not on the differential evolution between sectors, and changes to the results in all tables and figures in that study are barely noticeable.
} 
Table 3-Effect of Tariffs on Firm-Level Markups and Productivity (Logs)

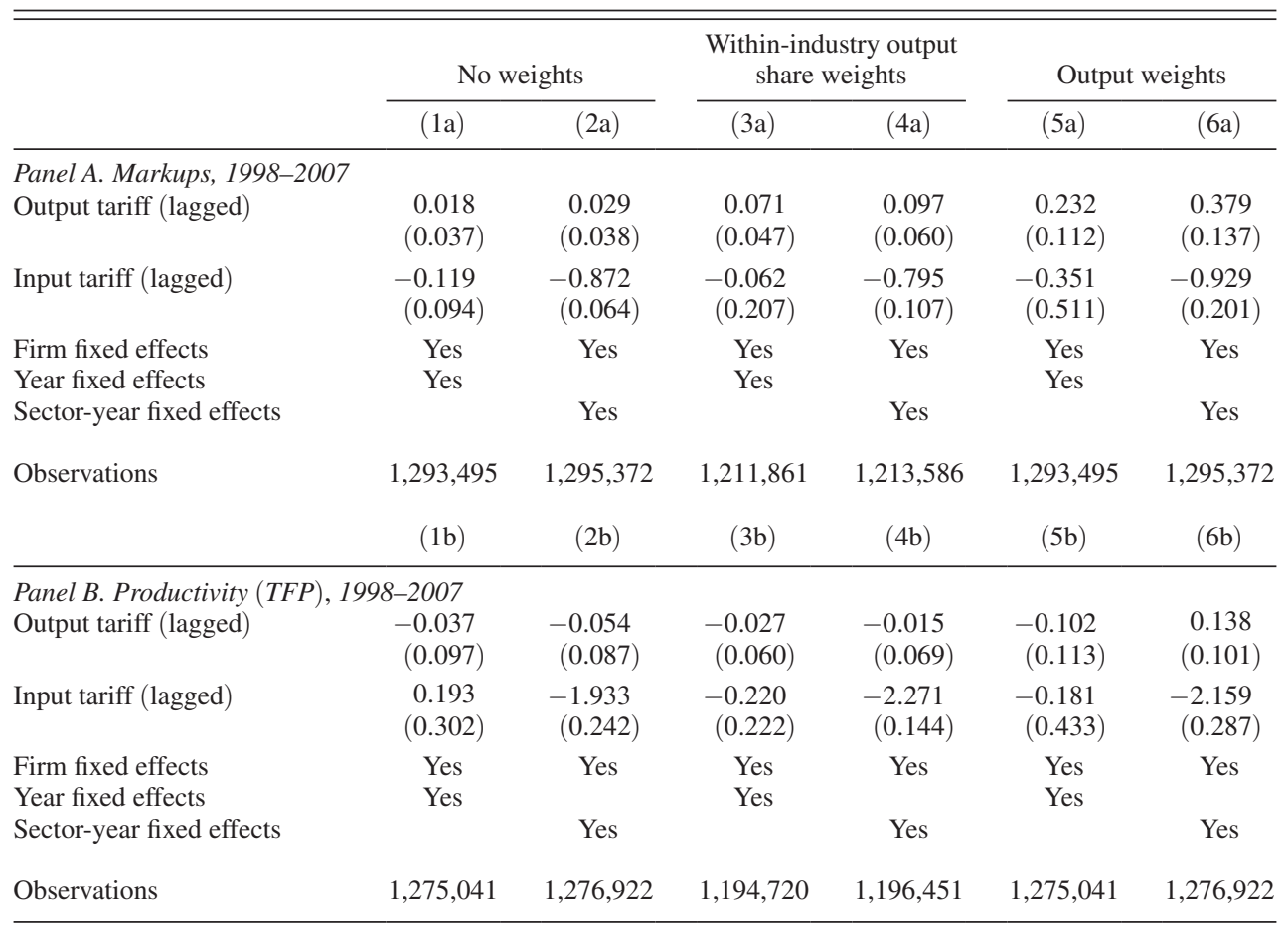

Notes: The instrument from 2001 onward is the maximum allowable tariff under the WTO agreement. The sample only includes firms that did not switch industry. Standard errors in parentheses are clustered two-ways at the industry-year and the firm level.

Table 3(b).--In panel B, where productivity is the dependent variable, the point estimates on the input tariff variable change slightly, but the overall pattern of a negative effect of input tariffs remains. Changes are more pronounced for the point estimates on the output tariff variable. Although signs of five of the six estimates remain negative, statistical significance is lost throughout.

Table 4.- In our analysis at the industry level, changes in panel A for the results using the price-cost markup as the dependent variable are again very minor. Even in panel $\mathrm{B}$, which reports the results using productivity as the dependent variable, changes are minor when we include industry fixed effect. The only notable changes are for the coefficients on the output tariff variable for the specification with industry-year weights. The point estimates become statistically insignificant in the first 3 columns, $1 \mathrm{~d}-3 \mathrm{~d}$.

Table 7.- - Here we investigated a possible mechanism for some of the results in Table 3 and Table 4 using a firm-level specification without firm-fixed effects. In the original article we limited our discussion to the coefficients on the output tariff variables in the productivity regressions. Similar to our revised estimates for Table 3 , these point estimates are not robust. None of the coefficients are significantly different from zero, which was also the case for results using the price-cost markup as dependent variable. 
Table 4-Decomposing the Effect of Tariffs on Industry Performance

\begin{tabular}{|c|c|c|c|c|c|}
\hline & $\begin{array}{l}\text { Total effect } \\
\text { (1a) }\end{array}$ & $\begin{array}{l}\text { Within } \\
(2 a)\end{array}$ & $\begin{array}{c}\text { Between } \\
(3 \mathrm{a})\end{array}$ & $\begin{array}{c}\text { Entry } \\
(4 a)\end{array}$ & $\begin{array}{c}- \text { Exit } \\
(5 a)\end{array}$ \\
\hline \multicolumn{6}{|c|}{ Panel A. Price-cost markups, 1998-2007 } \\
\hline Change in output tariff & $\begin{array}{c}0.093 \\
(0.057)\end{array}$ & $\begin{array}{c}0.091 \\
(0.037)\end{array}$ & $\begin{array}{r}-0.002 \\
(0.012)\end{array}$ & $\begin{array}{c}0.007 \\
(0.034)\end{array}$ & $\begin{array}{r}-0.002 \\
(0.009)\end{array}$ \\
\hline Change in input tariff & $\begin{array}{r}-0.382 \\
(0.129)\end{array}$ & $\begin{array}{r}-0.084 \\
(0.083)\end{array}$ & $\begin{array}{c}0.044 \\
(0.027)\end{array}$ & $\begin{array}{c}-0.345 \\
(0.078)\end{array}$ & $\begin{array}{c}0.002 \\
(0.020)\end{array}$ \\
\hline Industry fixed effects & Yes & Yes & Yes & Yes & Yes \\
\hline \multirow[t]{2}{*}{ Observations } & 844 & 844 & 844 & 844 & 844 \\
\hline & $(1 b)$ & $(2 b)$ & $(3 b)$ & $(4 b)$ & $(5 b)$ \\
\hline Change in output tariff & $\begin{array}{c}0.096 \\
(0.040)\end{array}$ & $\begin{array}{c}0.084 \\
(0.026)\end{array}$ & $\begin{array}{c}-0.021 \\
(0.008)\end{array}$ & $\begin{array}{c}0.042 \\
(0.022)\end{array}$ & $\begin{array}{c}-0.008 \\
(0.006)\end{array}$ \\
\hline Change in input tariff & $\begin{array}{r}-0.366 \\
(0.102)\end{array}$ & $\begin{array}{r}-0.140 \\
(0.067)\end{array}$ & $\begin{array}{c}0.042 \\
(0.020)\end{array}$ & $\begin{array}{r}-0.259 \\
(0.057)\end{array}$ & $\begin{array}{r}-0.010 \\
(0.015)\end{array}$ \\
\hline Industry-year weights & Yes & Yes & Yes & Yes & Yes \\
\hline \multirow[t]{2}{*}{ Observations } & 844 & 844 & 844 & 844 & 844 \\
\hline & (1c) & $(2 c)$ & $(3 c)$ & $(4 c)$ & $(5 c)$ \\
\hline \multicolumn{6}{|c|}{ Panel B. Productivity, 1998-2007 } \\
\hline Change in output tariff & $\begin{array}{r}-0.583 \\
(0.119)\end{array}$ & $\begin{array}{r}-0.100 \\
(0.059)\end{array}$ & $\begin{array}{c}0.041 \\
(0.031)\end{array}$ & $\begin{array}{r}-0.547 \\
(0.095)\end{array}$ & $\begin{array}{c}0.022 \\
(0.021)\end{array}$ \\
\hline Change in input tariff & $\begin{array}{c}-2.251 \\
(0.224)\end{array}$ & $\begin{array}{r}-1.050 \\
(0.130)\end{array}$ & $\begin{array}{c}0.323 \\
(0.058)\end{array}$ & $\begin{array}{c}-1.503 \\
(0.179)\end{array}$ & $\begin{array}{r}-0.020 \\
(0.038)\end{array}$ \\
\hline Industry fixed effects & Yes & Yes & Yes & Yes & Yes \\
\hline \multirow[t]{2}{*}{ Observations } & 844 & 844 & 844 & 844 & 844 \\
\hline & $(1 \mathrm{~d})$ & $(2 \mathrm{~d})$ & $(3 \mathrm{~d})$ & $(4 d)$ & $(5 d)$ \\
\hline Change in output tariff & $\begin{array}{c}-0.093 \\
(0.103)\end{array}$ & $\begin{array}{c}0.023 \\
(0.058)\end{array}$ & $\begin{array}{c}0.001 \\
(0.024)\end{array}$ & $\begin{array}{c}-0.125 \\
(0.067)\end{array}$ & $\begin{array}{c}0.008 \\
(0.014)\end{array}$ \\
\hline Change in input tariff & $\begin{array}{r}-1.645 \\
(0.208)\end{array}$ & $\begin{array}{r}-0.814 \\
(0.117)\end{array}$ & $\begin{array}{c}0.202 \\
(0.047)\end{array}$ & $\begin{array}{c}-1.008 \\
(0.154)\end{array}$ & $\begin{array}{c}-0.024 \\
(0.028)\end{array}$ \\
\hline Industry-year weights & Yes & Yes & Yes & Yes & Yes \\
\hline Observations & 844 & 844 & 844 & 844 & 844 \\
\hline
\end{tabular}

Notes: Separate regressions in each column. The instrument from 2001 onward is the change in the maximum allowable tariff under the WTO agreement. Dependent variables are the terms of a linear decomposition of the industry-level change in markup or productivity. The sample pools annualized growth rates over 2 subperiods (1998-2001 and 2001-2007) that cover 424 and 420 industries, respectively. Standard errors in parentheses.

We show updated versions of Table 3, Table 4, and Table 7.

\section{Implications for the Findings}

Although all point estimates in Table 3 and Table 4 change to some degree, the signs and magnitudes of most effects are not materially affected. Only a few of the changes are large enough to modify any of the economic implications of analysis. Most importantly, all estimates relating to the effects of tariffs on markups, which is the most novel contribution in the article, are robust.

One effect that is not robust is the productivity-enhancing effect of a cut in output tariffs when it is estimated at the firm level. Since all specifications in Table 3 include firm-fixed effects, this parameter is identified from year-on-year changes for 
Table 7-Effect of Tariffs on the Level of Markup and Productivity by Firm Status

\begin{tabular}{lcc}
\hline \hline & Markup & Productivity \\
& $(1)$ & $(2)$ \\
\hline $\begin{array}{l}\text { Output tariff (lagged) } \\
\times \text { Incumbent }\end{array}$ & -0.041 & 0.037 \\
& $(0.025)$ & $(0.046)$ \\
$\times$ Entrant & -0.030 & 0.064 \\
& $(0.043)$ & $(0.056)$ \\
$\times$ Exiting firm & -0.024 & 0.041 \\
& $(0.039)$ & $(0.059)$ \\
Input tariff (lagged) & & \\
$\times$ Incumbent & -0.059 & 0.487 \\
& $(0.067)$ & $(0.142)$ \\
$\times$ Entrant & 0.038 & 0.202 \\
& $(0.117)$ & $(0.180)$ \\
$\times$ Exiting firm & -0.063 & 0.254 \\
& $(0.109)$ & $(0.174)$ \\
Industry fixed effects & & Yes \\
Year by firm-status interaction fixed effects & Yes & Yes \\
Observations & & 904,960 \\
\hline
\end{tabular}

Notes: Sample covers the period 1999-2006 and only includes firms that do not switch industry and survive for at least two years. For entrants and exiting firms we exclude, respectively, their first and last year of operation to avoid calculating productivity using output for less than a full year. The instrument from 2001 onward is the maximum allowable tariff under the WTO agreement. Standard errors in parentheses are clustered two-ways at the industry-year and at the firm level.

incumbent firms. The positive effect of tariff cuts on sectoral productivity, identified at the industry level and reported in Table 4, is robust. In particular, new entrants are still found to contribute especially strongly to productivity growth in industries that were liberalized. Such an effect for new entrants could coexist with the lack of a positive effect in the firm-level regressions because new firms in liberalized sectors are already more productive in the year that they enter. However, this is not the case, as the coefficient on output tariffs for entrants also becomes statistically insignificant in the specification without firm fixed effects, in column 2 of Table 7.

Thus, it must be the case that in the years following entry, newly entered firms are able to improve their productivity more rapidly in liberalized sectors. Brandt, Van Biesebroeck, and Zhang (2012) show that the productivity level of new firms at entry falls relative to incumbents over time, however post-entry their productivity still converges to the same level relative to incumbents as in earlier years. ${ }^{\beta}$ This reflects a systematic pattern of rapid productivity growth by new entrants, which seems to take place disproportionately in liberalized industries. To rationalize such a pattern in the absence of a positive coefficient in the firm-level results of Table 3 we propose 3 , not mutually exclusive, explanations.

First, new firms at entry tend to be relatively small in size and thus are likely to contribute little to the weighted results in Table 3. Note that in the unweighted results, in columns $1 b$ and $2 b$, the point estimates are more negative. Second, all

\footnotetext{
${ }^{3}$ Figure 5 in Brandt et al. (2012) shows that 2 to 3 years after entry, new firms achieve a productivity premium of approximately 10 percent relative to firms that are active over the entire 1998-2007 sample period.
} 
year-on-year changes contribute to the estimation of the firm-level effects, while only entrants that survive to the end of the subperiod in which they enter contribute to the identification of the entrants' effect in Table 4. Lower surviving rates for poorly performing entrants, which is plausible, would help explain the different results in the two tables. $\square^{4}$ Third, as argued in the paper, it is important to use weights in the regressions because we use the same industry deflator for all firms. Note, however, that in Table 4 the productivity levels of new entrants are aggregated using only the weights of entrants. As output tariff cuts tend to lower markups of incumbents more than the markups of entering firms - compare the effect in $4 \mathrm{a}$ and $2 \mathrm{a}$ or $4 \mathrm{~b}$ and $2 \mathrm{~b}$ - we are under-deflating entrants' output and overestimating their productivity in liberalized industries. While the implied impact of the differential price adjustment is small, this also contributes to the negative correlation between productivity and output tariffs for entrants in Table 4.

We regret the mistake in the construction of the input price deflators, especially in light of their use by other researchers studying the Chinese economy. In any analysis where material input use is considered, it is important to use the updated series which is now also available through the AER's website. 5

\section{REFERENCES}

Brandt, Loren, Johannes Van Biesebroeck, Luhang Wang, and Yifan Zhang. 2017. "WTO Accession and Performance of Chinese Manufacturing Firms." American Economic Review 107 (9): 27842820.

Brandt, Loren, Johannes Van Biesebroeck, and Yifan Zhang. 2012. "Creative Accounting or Creative Destruction? Firm-Level Productivity Growth in Chinese Manufacturing." Journal of Development Economics 97 (2): 339-51.

\footnotetext{
${ }^{4}$ Exit of new entrants is quite common: approximately 15 percent (20 percent) of entrants exit within 2 (3) years after entering.

${ }^{5}$ It is not surprising that the estimates in Table 3 change the most when the specification also includes sector-year fixed effects. In this case the identification comes exclusively from differences in growth rates between four-digit industries within the same two-digit sector, which is exactly the type of comparison directly affected by the mistake.
} 